\title{
Local Wisdom in Learning Materials of Indonesian for Foreign Speaker at Sebelas Maret University
}

\author{
Lilis Fitriani $^{1,}$ Raheni Suhita $^{2,}$ Kundharu Saddhono ${ }^{3}$ \\ ${ }^{123}$ Pascasarjana Universitas Sebelas Maret, Indonesia. \\ ${ }^{1}$ lilisfitriani99@gmail.com
}

\begin{abstract}
Indonesian Language can be a symbol of national identity and the tool to unify people with different social, cultural, religion, and vernacular background. Besides, Indonesian Language functions as a modern communication medium in conducting the government, education, and science development. Nowadays, Indonesian Language becomes one of important languages in the world through the program of BIPA (Bahasa Indonesia for Foreign Speaker). This study aims to find out the local wisdom in the learning material of BIPA UNS. Descriptive qualitative is used for the methodology with the approach of local wisdom. Data collection is done through document analysis and in-depth interview. Repeated reading and context focusing on the local content material is done to analysis the data. The results showed that BIPA learning material contains the cultural aspect of local content and the language of communication used in the learning material is Indonesian Language.
\end{abstract}

Keywords: Foreign speakers, Local Wisdom, and Learning Materials.

\section{PENDAhuluan}

Indonesia beragam akan suku budaya dan bahasa. Budaya juga merupakan alat dalam produksi dan pertukaran makna melalui bahasa dan pengalaman-pengalaman masyarakat [1]. Bahasa merupakan perwujudan perasaan sebagai wujud dari budi manusia. Peran bahasa sangat berpengaruh dalam kehidupan manusia. Hal ini dikarenakan bahasa tidak hanya bagian dari kebudayaan melainkan juga penentu dari perkembangan kebudayaan itu sendiri.

Bahasa dan kebudayaan tidak hadir terisolasi serta akan selalu berubah sebagai akibat hubungannya secara internal kelompok masyarakat yang membentuknya dan pengaruh dari interaksinya dengan bahasa dan kebudayaan yang lain [2]. Dengan demikian tidak dipungkiri bahwa hampir tidak ada bahasa yang sama tidak terpengaruh oleh bahasa lain. Bahasa dan budaya dapat membentuk karakter yang baik karena peranya yang signifikan dalam kesantunan berbahasa Indonesia. Akan tetapi, suatu bahasa yang dianggap santun oleh kelompok tutur tertentu belum tentu dianggap santun oleh kelompok tutur lain karena dalam pemakaian bahasa ditentukan oleh konteks dalam pemakaian bahasa tersebut. Melalui bahasa, selain dapat mengekspresikan pikirannya, manusia dapat menafsirkan dan mengonseptualisasikan dunia yang melingkupinya. Bahasa menempati posisi sangat sentral dalam kehidupan manusia karena mempunyai aspek majemuk [3]. Salah satu bukti kemajemukan bahasa adalah digunakannya bahasa Indonesia oleh 
mahasiswa penutur asing di UNS untuk mengenal dan menguasai lingkungannya, baik lingkungan sosial maupun lingkungan alam.

Bahasa yang digunakan oleh masayarakat Indonesia merupakan bahasa ketimuran, sehingga ada tata krama yang berlaku untuk tetap menjaga kearifan lokal bangsa Indonesia. Berkaitan dengan hal tersebut, bahasa masyarakat mencerminkan pandangan manusia serta penafsiran manusia terhadap segala sesuatu [4]. Hal ini sejalan dengan aturan yang dibuat oleh pemerintah pada Undang-undang No. 24 Tahun 2009 pasal 29 ayat 1 tentang penggunaan bahasa, di mana bahasa Indonesia wajib digunakan sebgai bahasa pengantar pendidikan. Berlandasakan Undangundang tersebut mahasiswa asing di UNS wajib mengikuti pembelajaran Bahasa Indonesia untuk Penutur Asing (BIPA) karena dapat memudahkan mahasiswa asing dalam berkomunikasi.

Dalam bidang pembelajaran bahasa, khususnya Bahasa Indonesia untuk Penutur Asing (BIPA) Suyitno[1] mengkaji tentang pengetahuan awal, prospek, dan perilaku belajar mahasiswa BIPA guna meningkatkan semangat belajar mahasiswa asing untuk mencapai hasil belajar yang tinggi. Penelitian ini ditujukan untuk (1) menemukan cara belajar mahasiswa asing untuk mencapai hasil belajar yang tinggi, (2) menemukan porgam baru bagi pengajar BIPA untuk mengembangkan desain studi agar menciptakan lingkungan belajar yang baik bagi mahasiswa asing. Beberapa penelitian lain yang berkaitan dengan BIPA antara lain oleh Saddhono [5] khususnya tentang sosiolinguistik yang menekankan pada konteks sosial agar dalam pengajaran bahasa Indonesia disesuaikan dengan konteks, karena dalam penerapan penggunaan bahasa Indonesia oleh mahasiswa asing dipengaruhi oleh bahasa Jawa. Berkaitan dengan BIPA sudah banyak diteliti. Akan tetapi penelitian yang berkaitan dengan BIPA dengan menggunakan pendekatan kearifan lokal dalam materi pembelajaran BIPA belum pernah diteliti.

Permasalahan dalam penelitian ini adalah fenomena kebahasaan oleh mahasiswa asing di UNS dengan kearifan lokal yang terkandung dalam materi pembelajaran BIPA di UNS. Kearifan lokal adalah kemampuan masyarakat dalam menghadapi pengaruh kebudayaan asing yang masuk di Indonesia. Kearifan lokal mengacu pada pengetahuan yang berasal dari masyarakat yang dapat diperoleh dari masyarakat kelompok maupun individu [4]. Kearifan lokal juga memberikan kontribusi terhadap terciptanya kehidupan yang damai dan tentram. Hana. E Joy, dan Schmidt Sarah Brown mengatakan bahwa penggunaan bahasa dalam percakapan pada dasarnya bersifat inkremental, dan dipandu oleh representasi bahawa lawan bicara mempertahankan pengetahuan dan keyakinan masing-masing [6]. Hal ini menimbulkan paradigma bahwa dalam pemrosesan bahasa khsusnya mahasiswa asing di UNS membutuhkan materi pembelajaran bahasa untuk memperoleh kompetensi pembelajaran yang diharapakan.

Materi pembelajaran BIPA yang digunakan harus meliputi empat keterampilan berbahasa yaitu menyimak, berbicara, membaca, dan menulis. Hal ini selaras dengan pendapat Saddhono yang mengatakan bahwa materi pembelajaran BIPA harus berkaitan dengan Indonesia agar lebih menarik dan mengenal Indonesia dari aspek budaya [5]. Dalam pengajaran BIPA untuk mencapai empat keterampilan berbahasa oleh makasiswa asing dapat dilakukan dengan meningkatkan bahan atau materi pembelajaran yang sesuai dengan kompetensi yang diharapkan. Materi pembelajaran adalah segala sesuatu yang digunakan oleh pengajar untuk memudahkan belajar dan meningkatkan pengalaman berbahasa[7]. Berdasarkan uraian di atas, kajian budaya dengan pendekatan kearifan lokal dalam materi pembelajaran BIPA menarik untuk dikaji agar lebih mengenal Indonesia yang tidak hanya dari aspek bahasa tetapi aspek lainnya baik lingkungan sosial, alam, dan budaya. Dengan demikian tujuan pembelajaran BIPA di UNS tidak hanya berfokus pada pemerolehan 
keterampilan berbahasa Indonesia yang baik, tetapi juga untuk memahami konteks kesopanan dan tata krama yang berlaku di Indonesia. Berkaitan dengan dengan hal tersebut, Bahasa dapat digunakan sebagai salah satu media untuk menganalisis aspek budaya termasuk konsep kesopanan. Konsep kesopanan merupakan salah satu kemampuan sosial untuk berinteraksi dengan orang lain agar diterima dalam suatu budaya tertentu[8]. Oleh karenanya, perlu diadakan suatu konsep kesopanan agar mahasiswa asing dapat beirnteraksi dan diterima dalam suatu limgkungan, baik lingkungan sosial alam dan budaya khususnya lingkungan sekitas UNS. Hal ini perlu diperhatikan karena dalam penerapannya mahsiswa penutur asing [9].

\section{METODE PENELITIAN}

Penelitian ini adalah penelitian deskriptif kualitataif. Pendekatan kualitatif bersifat deskriptif yang memandang bahwa tidak ada sistem tanda yang patut diremehkan. Semua penting, saling berkaitan dan mempunyai pengaruh dengan yang lain [10]. Penelitian ini meneliti objek penelitian secara holistik dan mendeskripsikan secara kata-kata. Prosedur analisis yang digunakan Prosedur analisis statistik atau cara kuantifikasi lainnya [11]. Maksud dan tujuan memilih jenis penelitian ini adalah untuk mengetahui fenomena yang dialami oleh subjek penelitian dengan pendeskripsikan cermat dalam pengumpulan data.

Penelitian ini menggunakan pendekatan berbasis kearifan lokal yang terkandung dalam materi pembelajaran BIPA di UNS. Dengan demikian, penelitian menggunakan data primer berupa materi pembelajaran BIPA yang akan menyajikan laporan penelitian berupa kutipan data dan gambar untuk mendeskripsikan kearifan lokal yang terkandung dalam materi pembelajaran BIPA di UNS. Kajian ini menggunakan teknik cuplikan yang bersifat purposive sampling. Kajian ini termasuk kajian kontekstual mengenai bahasa yang terjadi dalam suatu tuturan dengan memperhatikan konteks sosial yang menyertainya. Disamping itu kajian ini juga memperhatikan konteks keanakargaman budaya di Indonesia yang sudah terkenal di seluruh dunia [12]. Penyajian data dilakukan dengan perumusan melalui kata-kata berupa cuplikan yang disertai pemberian gambar.

\section{HASIL PENELITIAN}

Materi pembelajaran BIPA di UNS menggunakan pemakaian bahasa yang mampu mengenalkan mahasiswa asing tentang kebudayaan Indonesia. Dengan demikian, tujuan pembelajaran tidak hanya berfokus pada pemerolehan keterampilan berbahasa Indonesia yang baik, tetapi juga untuk memahami konteks kesopanan dan tata krama yang berlaku di Indonesia. Hal tersebut dapat dibuktikan dengan adanya kandungan kearifan lokal dalam konten materi pembelajaran, penggunan bahasa, serta gambar ilustrasi yang mencerminkan kekhasan budaya Indonesia.

Pemilihan bahasa yang digunakan dalam materi pembelajaran BIPA memiih konten tentang budaya sertakan ilustrasi yang dapat membuat materi pembelajarn lebih menarik dan dapat mempermudah mahasiswa penutur asing untuk memahami Indonesia dari segi konteks sosial dan budaya.
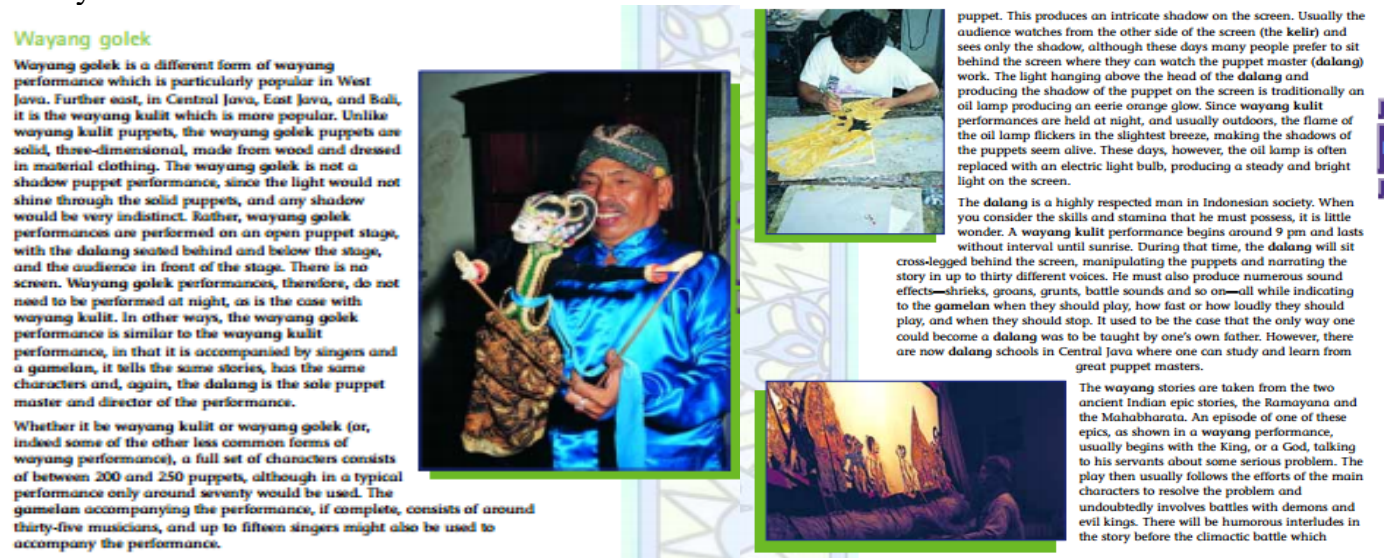


\section{Gambar 01. Ilustrasi Materi Pembelajaran BIPA di UNS}

Pada Gambar 01 materi yang digunakan adalah konteks budaya berupa wayang. Wayang merupakan salah satu produk budaya di Indonesia. Di dalam gambar 01 terdapat terdapat cuplikan kata "wayang golek is a different from of wayang performance wich is particularlypopular in West Java. Further east, in Central Java, East Java, and Bali, it is the wayang kulit which is more popular". Cuplikan ini hanyalah satu contoh kecil konteks budaya yang terdapat dalam materi pembelajaran BIPA di UNS. Berikut merupakan contoh penggunaan. Dengan demikian gambar ilustrasi yang terdapat dalam materi pembelajaran BIPA mengangkat tema budaya Indonesia di mana gambar tersebut menggambarkan kekhasan Indonesia. Berikut merupakan contoh produk budaya Indonesia selain wayang yang terdapat dalam pembelajaran BIPA di UNS seperti gambar becak, proses membatik, wayang kulit, wayang golek, rumah adat, keaadaan desa yang dikelilngi sawah, keraton, batik, pasar tradisional, andong, jamu, serta gambar candi-candi yang terdapat di indonesia.

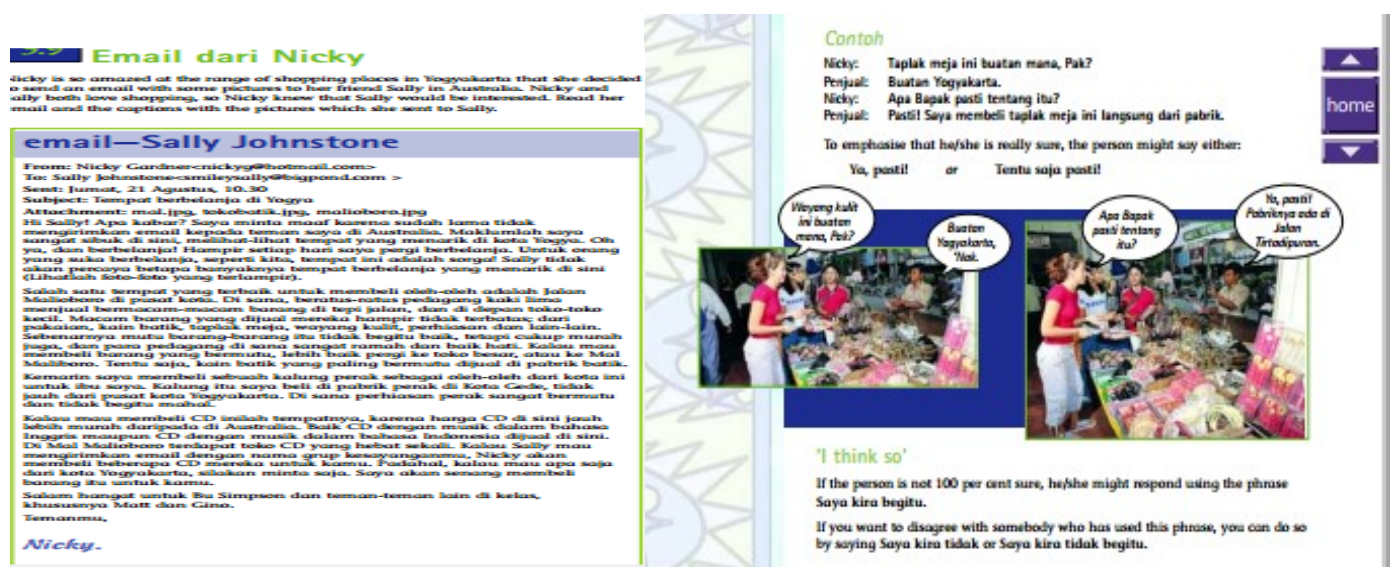

\section{Gambar 02. Konteks dan Konsep Materi Pembelajaran BIPA di UNS}

Pada gambar 02 terdapat cuplikan kata yang membahas tentang kota Yogyakarta tepatnya pada jalan Malioboro. Nicky dan ally yang merupakan penutur dalam teks materi pembelajaran tersebut membicarakan tentang keadaan jalan Malioboro yang ramai akan pedagang yang menjual 
bermacam-macam, dari kain batik, wayang, perhiasan dan pernak-pernik. Berikut cuplikan data tersebut:

"Salah satu tempat yang terbaik untuk membeli oleh-oleh adalah jalan Malioboro di pusat

kota. Di sana berates-ratus pedagang kaki lima menjual bermacam-macam barang di tepi jalan, dan di depan took-toko kecil. Macam-macam barang yang dijual mereka hampir tidak terbatas, dari pakaian batik, taplak meja, wayang kulit, perhiasan, dan lain-lain”.

Pada bagian tersebut jelaslah konteks pembahsan yang dibicarakan adalah keadaan sosial masyarakat kota Yogyakarta yang merupakan salah satu kota di Indonesia. Data selanjutnya adalah cuplikan kata yang menggambarkan keanekaragaman budaya di Indonesia. Berikut cuplikan data tentang keanekaragaman budaya Indonesia:

Penutur asing : Ida, kenapa Anda mengenakan jilbab?

Mitra tutur : Karena saya beragama Islam. Memakai Jilbab adalah kebiasaan wanita yang beragama Islam.

"when attending important meetings, parties or ceremonies such a weddings. Most adult

Indonesians wear their traditional style of clothing. This varies from one area to another, but

in Java men would wear a batik sarong with a shirt and a traditional style jacket, and perhaps

a peci".

Data tersebut menunjukkan bahwa dalam materi pembelajaran BIPA memuat unsur keanekaragaman budaya Indonesia. Konsep penggunaan teks dan konteks digambarkan dengan konteks sosial kesopanan yang meliputi keanekaragaman Indonesia di mana keanakaragaman tersebut merupakan alat pemersatu bangsa yang berlatar belakang berbeda dari suku, budaya, dan agama. Keanekaragamn di Indonesia yang termuat dalam materi pembelajaran BIPA menunjukkan kearifan lokal yang terdapat di Indonesia [13].

\section{SIMPULAN}

Berdasarkan pembahasan di atas, dapat disintesiskan bahwa materi pembelajaran BIPA di UNS mengandung kearifan lokal yang bertujuan untuk membuat materi pembelajaran lebih menarik dan membantu mahasiswa asing di UNS lebih mengenali Indonesia dari aspek budaya dengan kearifan lokal yang terkandung di dalamnya. Aspek budaya dan keanekaragaman yang digambarkan sangat dominan.

Materi pembelajaran BIPA yang digunakan dalam konteks kelembagaan menggambarkan pengajaran yang baik dari segi materi maupun pengetahuan budaya yang berpotensi membentuk karakter yang positif dengan sistem kepercayaan berbeda yang terkait kelompok tutur yang berbeda di mana bahasa Indonesia digunakan.

\section{REFERENCES}

[1] I. Suyitno, "Pengembangan Bahan Ajar Bahasa Indonesia untuk Penutur Asing (BIPA) berdasarkan Hasil Analisis Kebutuhan Belajar," Wacana, J. Humanit. Indones., 2007.

[2] "Bahasa, Kekuasaan, Dan Resistansinya: Studi Tentang Nama-Nama Badan Usaha Di Daerah Istimewa Yogyakarta," Humaniora, 2014.

[3] H. B. Mardikantoro, "Satuan Lingual Pengungkap Kearifan Lokal Dalam Pelestarian Lingkungan," Bhs. dan Seni J. Bahasa, Sastra, Seni dan Pengajarannya, vol. 44, no. 1, pp. 047-059, 2016. 
[4] J. Pepindhan and O. F. Human, "Tentang aktivitas manusia dalam bahasa jawa," pp. 150162.

[5] K. Saddhono, "Kajian Sosiolinguistik Pemakaian Bahasa Mahasiswa Asing Dalam Pembelajaran Bahsa Indonesia Untuk penutur Asing (BIPA) di Universitas Sebelas Maret," Kaji. Linguist. dan Sastra, 2012.

[6] S. Brown-Schmidt and J. E. Hanna, "Talking in another person's shoes: Incremental perspective-taking in language processing," Dialogue \& Discourse, vol. 2, no. 1, pp. 1133, 2011.

[7] N. Nuruddin, "Analisis Kebutuhan Bahan Ajar Bahasa Arab Bagi Calon Tenaga Kerja Indonesia (Tki) Di Timur Tengah," Bhs. dan Seni J. Bahasa, Sastra, Seni dan Pengajarannya, vol. 44, no. 2, pp. 149-161, 2016.

[8] D. B. Jawa-, "Inti," no. April, pp. 17-24, 2010.

[9] K. Siswa and S. M. K. Di, "Fenomena penggunaan unggah-ungguh basa jawa kalangan siswa smk di surakarta," pp. 145-156, 2019.

[10] R. Bogdan and S. K. Biklen, "Bogdan, R. C \& Biklen, S. K. (2003). Qualitative Research for Education: An introduction to Theories and Methods (4th ed.). New York: Pearson Education group. (pp. 110-120).," Qual. Res. Educ. An Introd. to Theor. Methods, 2003.

[11] D. M. A. Lexy J. Moleong, "Metodologi Penelitian Kualitatif (Edisi Revisi)," PT. Remaja Rosda Karya, 2019.

[12] B. Ibu et al., "Di Maluku Utara ) Ibu Language Which Lost It ' S " Mother ' ( Sociolinguistics Study of Endangered Language in North Moluccas )," vol. 19, no. 3, pp. 419-434, 2017.

[13] K. Saddhono, "Integrating culture in Indonesian language learning for foreign speakers at Indonesian universities," J. Lang. Lit., vol. 6, no. 2, 2015. 
